\title{
Future Learning Strategy and ePortfolios in Education
}

\author{
Christian Dorninger and Christian Schrack \\ Austrian Federal Ministry for Education, the Arts and Culture \\ www.bmukk.gv.at; www.e-portfolio.at
}

\begin{abstract}
Based on the experience of a long running eLearning initiative the "Futur(e)Learning"-strategy was started October 2007: New forms of learning and "Web 2.0" didactics were launched at Austrian schools. The current results of this educational project will be outlined. The introduction of ePortfolios in education is part of this strategy: Portfolios are powerful tools to realize individualised learning in formal education (process portfolio) and they also support the documentation of skill oriented knowledge and informal acquired competences for the later professional career (application portfolio).
\end{abstract}

\section{The Futur(e)Learning Strategy}

The internet loses its pure "publication" function and is getting more and more interactive and user oriented in the sense of Web 2.0. This change concerns technical issues as well as all areas of application and using. In this context a new strategy for Austrian schools has been launched, based on the following focus points:

1) New forms of learning: by using non-directive learning arrangements it would be possible to gain results from group, partner and individual work.

2) Promotion of creativity: according to their natural talent the youth should get the chance to prepare their own creative thinking environment. Appropriate instruments like communication machines and learning management systems should help to find new ideas, realise own visions and learn important knowledge and behaviour patterns.

3) Using communication machines for mobile learning: all electronic devices like notebook PC, sub notebook, communicator, Classmate PC, PDA and web phone could become a communication machine for mobile learning!

Futur(e)Learning is part of the quality management initiative which is responsible for the implementation of evaluation culture at Austrian schools (Ministry of Education in Vienna, 2007). At the moment 220 schools are involved in Futur(e)Learning. The schools are supported by two eLearning knowledge networks, which were founded 2002: eLearning im Schulalltag (eLSA- lower secondary level) 
and eLearning Cluster Project (eLC - upper secondary level). Following projects have been launched in this framework:

1. eContent for all subjects and mid term IT-services for complete education

2. Social Software Support (Wikis, Weblogs, ePortfolios, Learning Communities)

3. Mobile phones for learning (connection with MOODLE platforms)

4. Teachers training with online academies and real time platforms

5. Equipment guidelines and equipment initiatives (for standardisation)

6. Educational offers for adult learners and employed persons (in an EU-ESFproject, especially for migration students)

7. Reduction of barriers for special target groups (isolated children and children in hospitals - project IICC)

8. Quality projects in schools and safer internet use (school development and educational standards, content production by teachers and students; ITsecurity)

9. Artistic-creative projects together with cultural institutions like the ARS Electronica Center Linz.

10. Introduction of ePortfolio in education

\section{Why ePortfolio Projects?}

ePortfolio captures the idea of lifelong learning and supports individuals moving along episodes of school, study, training and employment. The educational system should also prepare pupils and students for an active role on the modern labour market, which requires a dynamic evaluation of competencies. Due to the inherent portability of portfolios the smooth transfer of verifiable information about learning, evaluation and competences between the levels of education is ensured.

Based on experiences of several years of practice ePortfolios seem to demonstrate successfully the potential of serving individuals as well as organisations in a comprehensive way. According to the Chief Executive of the European Institute for eLearning (EIfEL), Serge Ravet "ePortfolios are now a central element in some national learning policies." [1] (RAVET, 2005). So it is safe to conclude that schools, higher education as well as enterprises are well advised to engage in the potentials of ePortfolios.

Portfolios are products of self organisation to support individual and collaborative learning processes at schools and they can deliver first experiences of students achievement maps on the way of lifelong learning. Portfolios can be seen to balance rather strict school quality management issues like education standards with prototypic tasks and test items. Both elements, strict and open approaches, must be implemented in a proper mixture to shape schools of tomorrow. Portfolios are personal reflection instruments to enrich traditional school work and university lectures. For students it is now possible to collect know-how and skills-oriented knowledge for their later professional careers. This approach also offers the chance for integrating informal und non-formal acquired knowledge and know-how in this personal competence tool. 
Portfolios can be used as personal learning instrument for students, as new assessment instrument at vocational schools and to prove competences and qualifications in the transition to the labour market as well. The process portfolio for reflected learning and the application portfolio are the two matching parts of this essential learning instrument (see fig. 1). On special occasions corresponding parts of the process portfolio would be extracted and prepared for assessment purposes and job application.

\section{Learning ePortfolio}

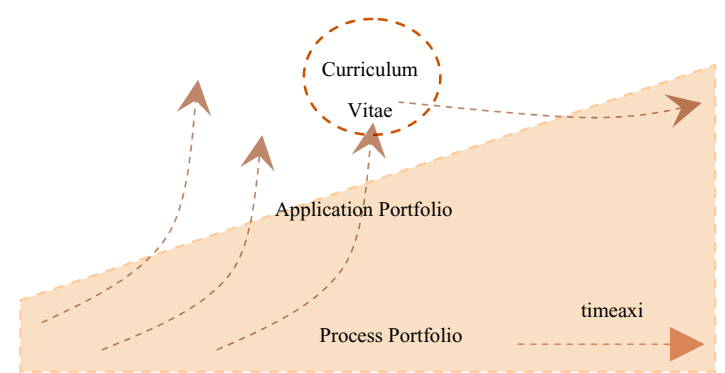

Fig. 1: Process and application portfolio

\section{3 ePortfolios in Austrian Schools and Adult Education}

Since examinations are not suitable for further teacher training, institutions like the "Pädagogischen Institute/Pädagogische Hochschulen" started using portfolios ten years ago. The experiences with Portfolios could be assumed as very well: Most of them include a learning diary, a documentation of lesson modules, personal reflections and evaluations of teaching and learning processes.

The idea of the Portfolio based on electronic documents (ePortfolio) was especially promoted by a conferences hold by "Salzburg Research" in 2005. Several secondary schools of the eLearning Cluster Austria decided to adapt the five-to-five model of Helen Barrett [2] (BARRETT, 2001) and launched first ePortfolio Projects with their students. The progress at secondary level also depends on the change of the final school leaving examination regulations ("Reife- und Diplomprüfungsvorschriften" in the Austrian VET-sector), which includes the management of larger engineering or business projects with focus on team work.

A good software environment can help to develop portfolio structures easily. One of the basic ideas behind ePortfolio concerns the transformation between the working/process portfolio and the presentation/application portfolio especially for graduation at school, during university studies and for job application.

There have been made lot software test on ePortfolios within the eLearning Cluster Project. Simple schemes like Wiki-lists or learning platform courses are under discussion as well as more complex structures like LMS - portfolio environments with comprehensive export functions. Benefits of the web 2.0 
transformation like social software or learning community tools are tested to establish a useful culture also for university demand. The portfolio module has been realized within the Moodle Platform with a special extension named Exabis portfolio (www.moodlekurse.org).

\section{Further Proceedings}

Portfolios are instruments for reflective and self - organized learning. Learning should be organized in groups using the classroom setting. Learning Management Systems (LMS) are the good tools for co-operative and collaborative learning. The LMS offers structural support to work with learning projects and case studies and, enables instances for individual or partner reflection and feedback of the peer group" (Peer Evaluation).

The main challenge is now to find criteria and indicators for the implementation of ePortfolios at schools, universities, in adult education and even for personnel managers for the labour market. Portfolios for pupils, students and any learners are only useful, if there is a common framework of content demands and technical environments from school to university and even to lifelong learning.

The expertise and the evaluation should not only be in the hand of teachers, the students themselves can give support to each other. In LMS groups it is common that students read contributions of others, especially if they are encouraged to do so. The students get an active role to knowledge-"acquisition" and the teachers are coaching this process as experts. The coaching role in a constructivism manner means that the teacher enables the learners to reach the self directed targets in different ways.

To optimise this learning process social effects and the teamwork should be explicitly enforced. Community learning spends higher motivation as learning single [3] (Lave und Wenger, 1991). To copy others' work is welcome. This kind of learning offers chances for complex peer coaching processes in classroom. In this way Learning Management System and ePortfolio are ideal complementary instruments for sustainable learning processes against the state of art educational background of differentiation and individualisation.

\section{References}

[1] RAVET, S., (2005) ePortfolio for a learning society, eLearning Conference, Brussels, May 19-20 2005, http://www.elearningconference.org/key_speaker/ravet.htm

[2] BARRETT, H.C.; (2001) ePortfolios in K-12 and Teacher Education, ISTEPresentation, Anchorage. Methodically their role in

[3] LAVE, E,; WengER, E.; (1991) Situated Learning. Legitimate peripheral participation, Cambridge. 